\title{
Introducción al Sistema Interamericano de protección de los derechos humanos y procedimiento ante sus órganos de tutela
}

\section{Leandro Kunusch y Martiniano Greco}

\section{Nacimiento y consolidación del Sistema Interamericano de Protección de los Derechos Humanos}

La organización internacional de los Estados en América data de una antigüedad bicentenaria, puesto que reconoce antecedentes ya en los primeros años de la independencia: como es lógico, se hizo menester la existencia de colaboración recíproca entre los diferentes territorios que iban progresivamente independizándose del Imperio Español en América, a los efectos de enfrentar los peligros provenientes del mundo europeo colonialista ${ }^{1}$.

En el marco de este espíritu asociativo, una pluralidad de Congresos fueron precariamente convocados y celebrados durante el transcurso del siglo XIX, los cuales sirvieron de cimientos a la célebre Conferencia Internacional Americana -Washington, 1890- en la cual se crea la Unión Internacional de Repúblicas Americanas, punto de inicio de múltiples Conferencias Interamericanas con mayor grado de institucionalización y, con ellas, de una larga construcción que derivaría en el hoy vigente Sistema Interamericano de Integración y de protección de los Derechos Humanos. Precisamente del seno de una de estas conferencias -la novena, celebrada en Bogotá, en 1948-, es que nace la Organización de los Estados Americanos (en adelante, OEA), por medio de la adopción de la Carta de la OEA (en adelante, COEA), tratado multilateral que entraría en vigor en diciembre de 1951.

1 Barboza, Julio, “Derecho Internacional Público", 2 Edición, Ed. Zavalía, Buenos Aires, 2008, p. 648. 
La OEA es una organización internacional intergubernamental regional, de la cual forman parte 35 Estados del continente americano, cuya finalidad -según el artículo 1 de la COEA- es lograr entre los Estados Americanos “...un orden de paz y de justicia, fomentar su solidaridad, robustecer su colaboración $y$ defender su soberanía, su integridad territorial y su independencia...", con relación a lo cual, en el artículo 2, se enumeran como propósitos "a) Afianzar la paz y la seguridad del Continente; b) Promover y consolidar la democracia representativa dentro del respeto al principio de no intervención; c) Prevenir las posibles causas de dificultades y asegurar la solución pacifica de controversias que surjan entre los Estados miembros; d) Organizar la acción solidaria de éstos en caso de agresión; e) Procurar la solución de los problemas politicos, jurídicos y económicos que se susciten entre ellos; f) Promover, por medio de la acción cooperativa, su desarrollo económico, social y cultural; g) Erradicar la pobreza crítica, que constituye un obstáculo al pleno desarrollo democrático de los pueblos del hemisferio, y b) Alcanzar una efectiva limitación de armamentos convencionales que permita dedicar el mayor número de recursos al desarrollo económico y social de los Estados miembros".

En el marco de la Organización de las Naciones Unidas (en adelante, ONU) nacida de los escombros de la fracasada Sociedad de las Naciones ${ }^{2}$, la OEA constituye un organismo regional ${ }^{3}$, creado al amparo del artículo 52 de la Carta de las Naciones Unidas (en adelante, CNU), que establece en su párrafo $1^{\circ}$ que "Ninguna disposición de esta Carta se opone a la existencia de acuerdos $u$ organismos regionales cuyo fin sea entender en los asuntos relativos al mantenimiento de la paz y la seguridad internacionales y susceptibles de acción regional, siempre que dichos acuerdos $u$ organismos, y sus actividades, sean compatibles con los Propósitos y Principios de las Naciones Unidas".

\footnotetext{
2 Hobsbawm, Eric, "Historia del siglo XX", 10 Edición, $10^{\circ}$ reimp., Ed. Crítica, Buenos Aires, 2013, p. 38.

3 Artículo 1 de la COEA
} 
Al igual que lo que sucedió en el seno de la ONU, donde luego de la adopción de la CNU se inició un proceso tendiente a la consagración de una plantilla de Derechos Humanos fundamentales de ineludible protección -naciendo la Declaración Universal de los Derechos Humanos, el Pacto Internacional de Derechos Económicos, Sociales y Culturales, el Pacto Internacional de Derechos Civiles y Políticos, etcétera-, en el seno de la OEA comenzaron a darse los primeros pasos hacia la promoción y defensa de los Derechos Humanos. Ello puesto que, por un lado, la COEA no los consagraba en forma detallada ni creaba órgano o institución alguna encargada de su defensa y protección, y por el otro, si bien en conjunto con la COEA -en Bogotá, 1948- se adoptó la Declaración Americana de los Derechos y Deberes del Hombre (en adelante, DADDH), por ser simplemente una resolución de la Conferencia -y no un tratado-, su carencia de fuerza vinculante ${ }^{4}$ llevó a la búsqueda de herramientas tendientes a dotar de operatividad y efectividad la nómina de derechos fundamentales. Con la creación de la Comisión Interamericana, en 1959, y la aprobación de su Estatuto en 1960, se fortalece el naciente Sistema Interamericano de Protección de los Derechos Humanos, mas no fue sino hasta el año 1969 que los Estados miembros de la OEA consolidaron el bloque de tutela: en la Conferencia celebrada dicho año en la ciudad de San José de Costa Rica se aprueba la Convención Americana de Derechos Humanos (en adelante, CADH), que entró en vigor en 1978, fue aprobada por Argentina en 1984 por Ley 23.054, y dotada de jerarquía constitucional en 1994 -artículo 75 inc. 22 C.N. 5 .

Huelga decir que sin perjuicio de la mención de la COEA, la DADDH, y la CADH como los puntos neurálgicos del Sistema Interamericano de protección de los Derechos Humanos

\footnotetext{
4 Martin, Claudia - Rodriguez Pinzón, Diego, “La Prohibición de la Tortura y los Malos Tratos en el Sistema Interamericano. Manual para víctimas y sus defensores", Serie de Manuales de la OMCT, Vol. 2, Ed. Boris Wijkstrom, 2006, p. 29

5 Quiroga Lavié, Humberto - Benedetti, Miguel Angel - Cenicacelaya, María de las Nieves, "Derecho Constitucional Argentino", Tomo I, 2a ed., Ed. Rubinzal - Culzoni, Santa Fe, 2009, p. 570
} 
desarrollado en el seno de la OEA, este se encuentra compuesto por una pluralidad de Convenciones, Declaraciones, e instituciones varias nacidas en el marco de tales instrumentos o por resoluciones oficiales adoptadas en Conferencias, que convergen en conjunto a tal fin; v. gr., la Convención Interamericana para Prevenir y Sancionar la tortura; la Convención Interamericana sobre Desaparición Forzada de Personas; la Convención Interamericana para Prevenir, Sancionar y Erradicar la Violencia contra la Mujer; la Convención Interamericana para la Eliminación de todas las Formas de Discriminación contra las Personas con Discapacidad; el Instituto Interamericano de Derechos Humanos; etcétera. A su vez, la CADH ha sido posteriormente complementada por dos Protocolos: el Protocolo Adicional a la Convención Americana sobre Derechos Humanos en Materia de Derechos Económicos, Sociales y Culturales; y el Protocolo Relativo a la Abolición de la Pena de Muerte.

\section{La Comisión Interamericana de Derechos Humanos}

\subsection{Nacimiento, evolución y funcionamiento}

Convocados los representantes de los Estados americanos a la Quinta Reunión de Consulta de Ministros de Relaciones Exteriores -celebrada en Santiago de Chile en agosto de 1959-, en el marco de debates respecto de la adopción de medidas de promoción y protección de los derechos humanos se resuelve tanto la creación de una Comisión Interamericana de Derechos Humanos (en adelante, Comisión) cuya función primordial sería la de coadyuvar a la satisfacción de tales objetivos, como la aprobación de su Estatuto, en el cual se le conceden importantes funciones y atribuciones $\mathrm{y}$, entre otras previsiones, se dispone que la sede permanente de la Comisión sería la misma que aquella de la entonces Unión Panamericana -Washington D. C.-, en la actualidad sede de la Secretaría General de la OEA ${ }^{6}$.

\footnotetext{
6 Faúndez Ledesma, Héctor, “El Sistema Interamericano de Protección de los Derechos Humanos. Aspectos institucionales y procesales", $3^{\circ}$ edición, Instituto Interamericano de Derechos Humanos, San José, Costa Rica, 2004, p. 36.
} 
La circunstancia de que la Comisión no fuera creada por un tratado o por reforma de la COEA sino por una simple resolución de un órgano de la OEA aprobada en Conferencia sólo por la mayoría de sus miembros, fue motivo de protesta por algunos Estados, dada la debilidad de la fuerza de sus actos en la tarea protección de los Derechos Humanos. Es así que en los hechos este órgano fue estructurado como una entidad destinada a la promoción de tales Derechos fundamentales -consagrados en la DADDH- en los Estados partes de la OEA, careciendo de potestades eficaces para garantizar su tutela ${ }^{7}$. Esta falencia fue salvada casi una década después -año 1967-, por medio del Protocolo de Buenos Aires reformador de la COEA, incluyendo a la Comisión en su texto y transformándola en un órgano principal de la OEA, con la misión -según el artículo 112 de la COEA- de promover la observancia y protección de los Derechos Humanos -previstos por entonces en la DADDH-.

A su vez, la inclusión de la Comisión en el articulado de la $\mathrm{CADH}$, junto con el otorgamiento en dicho instrumento de funciones adicionales, provocó que este órgano adquiriera un doble marco de desenvolvimiento -más precisamente, una dualidad de cometidos y atribuciones-, según que el Estado parte de la OEA que se encuentre involucrado en el asunto ventilado haya o no ratificado la $\mathrm{CADH}^{8}$, asumiendo en el primer caso importantes facultades de índole judicial, y desplegando en el segundo caso sus competencias originarias esencialmente de supervisión? . A todo evento, cabe destacar que en la actualidad, respecto de los Estados que ratificaron la Convención, el instrumento preponderantemente aplicable es este último, deviniendo subsidiaria -aunque plenamente vigente- la DADDH, de fundamental importancia en los casos relativos

\footnotetext{
Ibidem, p. 49.

8 Martin, Claudia y ot., cit., p. 30.

9 Faúndez Ledesma, Héctor, cit. p. 52.
} 
a países miembros de la OEA que no han ratificado la $\mathrm{CADH}, \mathrm{y}$ que en consecuencia son evaluados a la luz de aquella ${ }^{10}$.

\subsection{Composición}

Es un órgano compuesto por siete miembros, quienes según el artículo 34 de la CADH deberán ser personas de alta autoridad moral y reconocida versación en materia de derechos humanos, y que son elegidos por la Asamblea General de la OEA en base a una lista de candidatos propuestos por los gobiernos de los Estados miembros -artículo 36 de la $\mathrm{CADH}-$, para cumplir un período en funciones de cuatro años, pudiendo ser reelegidos por una sola vez -artículo 37 de la CADH-. Es dable destacar que este último precepto también dispone que no puede formar parte de la Comisión más de un nacional de un mismo Estado.

\subsection{Atribuciones}

De acuerdo a lo que hemos visto, la Comisión ejerce determinadas competencias según exista o no ratificación de la CADH del Estado parte de la OEA. Las mismas se encuentran enumeradas en los artículos 18 a 20 del Estatuto de la Comisión (en adelante, EC) vigente, aprobado por Resolución de la Asamblea General de la OEA en 1979:

"Artículo 18: Respecto a los Estados miembros de la Organización de los Estados Americanos, la Comisión tiene las siguientes atribuciones: a. estimular la conciencia de los derechos humanos en los pueblos de América; b. formular recomendaciones a los gobiernos de los Estados para que adopten medidas progresivas en favor de los derechos humanos, dentro del marco de sus legislaciones, de sus preceptos constitucionales y de sus compromisos internacionales, y también disposiciones apropiadas para fomentar el respeto a esos derechos; c. preparar los estudios o informes que considere convenientes para el desempeño de sus funciones; d. solicitar que

10 Ídem. 
los gobiernos de los Estados le proporcionen informes sobre la medidas que adopten en materia de derechos humanos; e. atender las consultas que, por medio de la Secretaría General de la Organización, le formule cualquier Estado miembro sobre cuestiones relacionadas con los derechos humanos en ese Estado y, dentro de sus posibilidades, prestar el asesoramiento que le soliciten; f. rendir un informe anual a la Asamblea General de la Organización, en el cual se tenga debida cuenta del régimen jurídico aplicable a los Estados partes en la Convención Americana sobre Derechos Humanos y de los Estados que no son parte; g. practicar observaciones in loco en un Estado, con la anuencia o a invitación del gobierno respectivo, $\mathrm{y} h$. presentar al Secretario General el programa-presupuesto de la Comisión para que éste lo someta a la Asamblea General".

"Artículo 20: En relación con los Estados miembros de la Organización que no son partes de la Convención Americana sobre Derechos Humanos, la Comisión tendrá, además de las atribuciones señaladas en el artículo 18, las siguientes: a. prestar particular atención a la tarea de la observancia de los derechos humanos mencionados en los artículos I, II, III, IV, XVIII, XXV y XXVI de la Declaración Americana de los Derechos y Deberes del Hombre; b. examinar las comunicaciones que le sean dirigidas y cualquier información disponible; dirigirse al gobierno de cualquiera de los Estados miembros no partes en la Convención con el fin de obtener las informaciones que considere pertinentes y formularles recomendaciones, cuando lo considere apropiado, para hacer más efectiva la observancia de los derechos humanos fundamentales; c. verificar, como medida previa al ejercicio de la atribución prescrita en el inciso b. anterior, si los procesos y recursos internos de cada Estado miembro no parte en la Convención fueron debidamente aplicados y agotados".

"Artículo 19: En relación con los Estados partes en la Convención Americana sobre Derechos Humanos, la Comisión ejercerá sus funciones de conformidad con las atribuciones previstas en aquella y en el presente Estatuto 
y, además de las atribuciones señaladas en el artículo 18, tendrá las siguientes: a. diligenciar las peticiones y otras comunicaciones, de conformidad con lo dispuesto en los artículos 44 al 51 de la Convención; b. comparecer ante la Corte Interamericana de Derechos Humanos en los casos previstos en la Convención; c. solicitar a la Corte Interamericana de Derechos Humanos que tome las medidas provisionales que considere pertinentes en asuntos graves y urgentes que aún no estén sometidos a su conocimiento, cuando se haga necesario para evitar daños irreparables a las personas; $d$. consultar a la Corte acerca de la interpretación de la Convención Americana sobre Derechos Humanos o de otros tratados sobre la protección de los derechos humanos en los Estados americanos; e. someter a la consideración de la Asamblea General proyectos de protocolos adicionales a la Convención Americana sobre Derechos Humanos, con el fin de incluir progresivamente en el régimen de protección de la misma otros derechos y libertades, y f. someter a la Asamblea General, para lo que estime conveniente, por conducto del Secretario General, propuestas de enmienda a la Convención Americana sobre Derechos Humanos".

A su vez, este último artículo se complementa con el artículo 41 de la $\mathrm{CADH}$, que establece las funciones que corresponden a la Comisión en el marco de dicho instrumento. Las previstas en los primeros cinco incisos, eminentemente políticas y diplomáticas, son propias de su misión de promoción de los Derechos Humanos $^{11}$. La prevista en el sexto inciso, alude a su función de protección que de ellos se le asigna:

"Artículo 41: La Comisión tiene la función principal de promover la observancia y la defensa de los derechos humanos, y en el ejercicio de su mandato tiene las siguientes funciones y atribuciones: a) estimular la conciencia de los derechos humanos en los pueblos de América; b) formular recomendaciones, cuando lo estime

11 Ibídem, p. 229 
conveniente, a los gobiernos de los Estados miembros para que adopten medidas progresivas en favor de los derechos humanos dentro del marco de sus leyes internas y sus preceptos constitucionales, al igual que disposiciones apropiadas para fomentar el debido respeto a esos derechos; c) preparar los estudios e informes que considere convenientes para el desempeño de sus funciones; d) solicitar de los gobiernos de los Estados miembros que le proporcionen informes sobre las medidas que adopten en materia de derechos humanos -a su vez, como contracara de este inciso, el artículo 43 obliga a los Estados partes a proporcionar a la Comisión las informaciones que ésta les solicite sobre la manera en que su derecho interno asegura la aplicación efectiva de cualesquiera disposiciones de la $\mathrm{CADH}-$; e) atender las consultas que, por medio de la Secretaría General de la Organización de los Estados Americanos, le formulen los Estados miembros en cuestiones relacionadas con los derechos humanos y, dentro de sus posibilidades, les prestará el asesoramiento que éstos le soliciten; f) actuar respecto de las peticiones y otras comunicaciones en ejercicio de su autoridad de conformidad con lo dispuesto en los artículos 44 al 51 de esta Convención, y g) rendir un informe anual a la Asamblea General de la Organización de los Estados Americanos".

En definitiva, como órgano previsto en la COEA, cumple determinadas funciones detalladas en su Estatuto, adquiriendo importancia vital la DADDH; a su vez, como órgano previsto en la $\mathrm{CADH}$, respecto de aquellos países que la han ratificado, cumple atribuciones adicionales previstas en aquel instrumento y también enumeradas en su Estatuto.

\subsection{Su actuación ante peticiones individuales y comunicaciones estatales [artículos 19 inc. a) EC y 41 inc. f) $\mathrm{CADH}$}

Dijimos que el ejercicio de la mayor parte de las atribuciones asignadas a la Comisión importa el despliegue de actos 
diplomáticos de los miembros de la Comisión; sin embargo, en lo que respecta a su labor ante peticiones y comunicaciones que le sean sometidas mediando alegación de violaciones por parte de un Estado a uno o múltiples derechos consagrados por la CADH, la Comisión cumple una función distinta, instructora, de investigación al estilo Ministerio Público Fiscal.

El esquema de protección previsto por la CADH es dual. Cuando hablamos de "peticiones", debemos tener en cuenta que estamos ante reclamos -contra un Estado americano parte de la Convención- provenientes de individuos particulares considerados sujetos de derecho internacional ${ }^{12}$, en cuya cabeza se encuentra previsto el goce de la pluralidad de Derechos Humanos consagrados por dicho instrumento. A la par, cuando hablamos de "comunicaciones" nos encontramos ante denuncias formuladas por un Estado contra otro Estado parte -por igual causa que en el caso de petición-, consagrándose una legitimación desligada de la posición de víctima del reclamante -puesto que el Estado denunciante no lo es-.

En su tarea de entendimiento en ambos cauces de reclamo, la Comisión se encuentra sujeta a la observancia de determinados procedimientos establecidos normativamente, con funciones tanto de evaluación y decisión como de impulso del planteo hasta su conclusión, y con prerrogativas inquisitivas, recorrido cuyo tránsito y cumplimiento deriva en un pronunciamiento suyo respecto del asunto -la Comisión debe oír a las partes e investigar los hechos, y tomar decisiones vinculantes para las partes-, todo lo cual ha llevado a afirmar que este despliegue en su conjunto importa el ejercicio de un verdadero cometido de carácter jurisdiccional ${ }^{13}$.

\footnotetext{
12 Fellay, Milton - Gonzalez Napolitano, Silvina, "Sujetos del Derecho Internacional", en "Lecciones de Derecho Internacional Público", Coord. Silvina Gonzalez Napolitano, Ed. Errepar, Buenos Aires, 2015, pp. 36-37.
}

13 Faúndez Ledesma, Héctor, cit. p. 229. 


\section{La Corte Interamericana de Derechos Humanos}

\subsection{Nacimiento y lineamientos generales sobre su funcionamiento}

Si bien ya en tiempos de creación de la OEA fueron varias las voces que se alzaron en reclamo del establecimiento de un tribunal que resulte competente para entender en los casos en que se aleguen violaciones a Derechos Humanos de las que proviniera la responsabilidad internacional de los Estados, la Corte Interamericana de Derechos Humanos (en adelante, Corte) es una verdadera "criatura" de la $\mathrm{CADH}^{14}$, que se instituyó en 1969 como parte de dicho Tratado, entró en vigencia en 1978 (al reunirse el número de países establecido por el instrumento para surtir tal efecto $)^{15}$, emitió su primera opinión consultiva en 1982 -OC-1/82- ${ }^{16}$, y falló su primer caso contencioso recién en 1988 -caso Velásquez Rodríguez vs. Honduras ${ }^{17}$.

Es un verdadero órgano judicial ${ }^{18}$, señalada por muchos como una auténtica justicia trasnacional/autoridad supranacional con amplias facultades para entender respecto de actos de

14 García Ramírez, Sergio, "La defensa de los derechos humanos. Reflexiones sobre la Corte Interamericana", en "La Ciencia del Derecho Procesal Constitucional”, División de Investigación, Legislación y Publicaciones del Centro Internacional de Estudios de la Corte Suprema de Justicia, e Instituto de Investigaciones Jurídicas de la Universidad Nacional Autónoma de México, Asunción, Paraguay, 2012, p. 142

15 Alvarado Llano, Lilian Carolina, "Los Fallos de la Corte Interamericana de Derechos Humanos y la Inobservancia de ellos por parte de los Gobiernos de algunos países miembros como atentado al respeto a los Derechos Humanos", en Revista Pensamiento Penal, artículo publicado en fecha 24(09/2015, disponible en formato digital en http://www.pensamientopenal.com.ar/doctrina.

16 A esta fecha, ha emitido 22 opiniones consultivas, siendo la última de ellas la OC-22/16, disponibles online todas ellas en http://www.corteidh.or.cr/CF/Jurisprudencia2/busqueda_opiniones_consultivas.cfm?lang=es

17 A esta fecha -octubre de 2016-, ha dictado 317 fallos, siendo el último el caso López Lone y ot. vs. Honduras, del 2 de septiembre de 2016. Pueden consultarse todos ellos online, formato documento digital, en http://www.corteidh.or.cr/CF/Jurisprudencia2/busqueda_casos_contenciosos.cfm

18 Martin, Claudia y ot., cit., p. 51 
autoridades nacionales o normas de derecho interno -incluso constitucionales- a la luz de la CADH y demás declaraciones y convenciones integrantes del Sistema Interamericano de Protección de los Derechos Humanos ${ }^{19}$.

Se trata de una instancia supraestatal para reforzar, desde el derecho internacional, la protección de los derechos cuando en sede interna de los Estados sufren violación, teniendo ellos raíz en la $\mathrm{CADH}$, que arbitra una jurisdicción contenciosa para los Estados que se hacen parte en el sistema. ${ }^{20}$ Sin perjuicio de ello, la CADH también habilita una instancia ante la Corte, ya no contenciosa sino solo consultiva, abierta a todos los Estados miembros de la OEA y demás organismos integrantes de ella.

\subsection{Composición}

Prevé el artículo 52 de la CADH que "la Corte se compondrá de siete jueces, nacionales de los Estados miembros de la Organización, elegidos a título personal entre juristas de la más alta autoridad moral, de reconocida competencia en materia de derechos humanos, que reúnan las condiciones requeridas para el ejercicio de las más elevadas funciones judiciales conforme a la ley del país del cual sean nacionales o del Estado que los proponga como candidatos, y agrega que "no debe haber dos jueces de la misma nacionalidad".

De acuerdo al artículo 53 de la $\mathrm{CADH}$, "serán elegidos, en votación secreta y por mayoría absoluta de votos de los Estados partes en la Convención, en la Asamblea General de la Organización, de una lista de candidatos propuestos por esos mismos Estados", agregando el artículo 54 que "serán elegidos para un período de seis años y sólo podrán ser reelegidos una vez"

El artículo 55 introduce una facultad interesante de los Estados miembros de la $\mathrm{CADH}$, cuando un caso sometido a

\footnotetext{
19 Sagüés, Néstor Pedro, "Manual de Derecho Constitucional", Ed. Astrea, Ciudad de Buenos Aires, 2007, pp. 67, 104, 615-616.

20 Bidart Campos, German J., "Manual de la Constitución Reformada", T. II, Ed. Ediar, Buenos Aires, 1998, p. 341
} 
la Corte lo tenga como parte, al disponer que sin perjuicio de que el juez que sea nacional de aquel conservará su derecho a conocer del mismo, "otro Estado parte en el caso -si lo hubierepodrá designar a una persona de su elección para que integre la Corte en calidad de juez ad hoc", a la vez que agrega que "si entre los jueces llamados a conocer del caso ninguno fuere de la nacionalidad de los Estados partes, cada uno de éstos podrá designar un juez ad hoc".

\subsection{Competencia consultiva}

Establece el artículo 64 de la CADH, en su primer párrafo, que "los Estados miembros de la Organización -y no solo miembros de la CADH- podrán consultar a la Corte acerca de la interpretación de esta Convención o de otros tratados concernientes a la protección de los derechos humanos en los Estados americanos", haciendo también extensiva esa facultad a los órganos enumerados en la COEA, actual artículo 53, entre los cuales se menciona a la Asamblea General; la Reunión de Consulta de Ministros de Relaciones Exteriores; los Consejos; el Comité Jurídico Interamericano; la Comisión Interamericana de Derechos Humanos; la Secretaría General; las Conferencias Especializadas, y los Organismos Especializados.

A su vez, en su segundo párrafo establece una facultad de consulta exclusiva para los Estados partes de la OEA -sin mencionar el resto de los órganos-, al disponer que "la Corte, a solicitud de un Estado miembro de la Organización, podrá darle opiniones acerca de la compatibilidad entre cualquiera de sus leyes internas y los mencionados instrumentos internacionales".

Esta función consultiva asignada a la Corte ha erigido un sistema que marcha a la par del procedimiento contencioso, ofreciendo una alternativa judicial cuyo objeto consiste en brindar herramientas a los Estados y a los diversos órganos parte de la OEA que les sirvan de auxilio para cumplir adecuadamente con las disposiciones emanadas de los Tratados Internacionales de Derechos Humanos, evitando el sistema sancionatorio propio 
del procedimiento confrontativo ${ }^{21}$-se trata de un procedimiento en el cual no hay partes ni litigio-y, por supuesto, coadyuvando al aseguramiento de la vigencia de los Derechos fundamentales protegidos por el Sistema Interamericano, por medio de la previsión de una amplia legitimación.

No nos detendremos en lo sucesivo en el procedimiento seguido a los efectos de efectuar una consulta, razón por la cual destacaremos en el presente acápite sólo algunas cuestiones de forma previstas por el Reglamento de la Corte Interamericana de Derechos Humanos. En esta línea, resulta de interés destacar que cuando se tratare de la interpretación de la $\mathrm{CADH}$, el Reglamento prescribe que las solicitudes de opinión consultiva deberán "formular con precisión las preguntas específicas sobre las cuales se pretende obtener la opinión de la Corte" -artículo 70-; si se solicitare la interpretación de otros tratados concernientes a la protección de los derechos humanos en los Estados americanos, dispone que deberá ser "identificado el tratado y las partes en él, las preguntas específicas sobre las cuales se pretende obtener la opinión de la Corte y las consideraciones que originan la consulta" -artículo 71-; y por último, si se tratare de la Interpretación de leyes internas, establece que la solicitud deberá señalar -entre otras cuestiones- "las disposiciones de derecho interno, así como las de la Convención o de otros tratados concernientes a la protección a los derechos humanos, que son objeto de la consulta, y las preguntas específicas sobre las cuales se pretende obtener la opinión de la Corte" -artículo 72-. Además, para el caso de que la consulta proviniere de uno de los órganos de la OEA, se señalará "la razón por la cual la consulta se refiere a su esfera de competencia" -artículos 71 y 72 -.

\subsection{Competencia contenciosa}

La CADH prevé tres tipos de competencias a los órganos por ella establecidos: una de promoción de los Derechos Humanos,

21 Faúndez Ledesma, Héctor, cit. p. 947 
que en sus diversas variantes concierne exclusivamente a la Comisión; una función consultiva asignada a la Corte; y una de protección de los Derechos Humanos, asignada conjuntamente a la Comisión y a la Corte $^{22}$-en lo que respecta a éste último órgano, por medio de la función decisora ejercida a través de su competencia contenciosa-.

Definición acertada es aquella que cataloga la competencia contenciosa de la Corte como la atribución de enjuiciar casos que conciernen presuntas violaciones de la CADH por los Estados partes de la misma ${ }^{23}$.

Si bien hemos visto que los individuos tienen capacidad procesal para someter ante la Comisión peticiones que contengan denuncias alegando la violación de la Convención ${ }^{24}$, carecen de la posibilidad de acudir de manera autónoma a la Corte, puesto que "sólo los Estados partes y la Comisión tienen derecho a someter un caso a la decisión de la Corte" -artículo 61 de la CADH-.

A su vez, la CADH es clara en el sentido de que "la Corte tiene competencia para conocer de cualquier caso relativo a la interpretación y aplicación de las disposiciones de esta Convención que le sea sometido, siempre que los Estados partes en el caso hayan reconocido o reconozcan dicha competencia" -artículo 62 inc. 3-. Esto hace que un Estado pueda ser parte de la CADH pero, a la vez, no reconocer la competencia de la Corte.

Existen diferentes maneras y modalidades de reconocer la competencia, previstas en el artículo 62 de la CADH. Puede hacerse por convención especial entre los Estados involucrados, o bien por declaración especial, la cual puede ser realizada en el momento del depósito de su instrumento de ratificación o adhesión de la $\mathrm{CADH}$, o en cualquier momento posterior; y a su

\footnotetext{
22 Faúndez Ledesma, Héctor, cit. p. 229

23 Martin, Claudia y ot., cit., p. 52

24 Faúndez Ledesma, Héctor, cit. p. 591
} 
vez, puede ser hecha incondicionalmente, o bajo condición de reciprocidad -en caso de denuncia interestatal-, por un plazo determinado o para casos específicos. En el caso concreto de nuestro país, al ratificar la $\mathrm{CADH}$, por medio del artículo 2 de la ley 23.054 se dispuso el reconocimiento de la competencia de la Corte "sobre todos los casos relativos a la interpretación o aplicación de esta convención, bajo condición de reciprocidad". 25

Pero lo dicho no es todo: "para que la Corte pueda conocer de cualquier caso, es necesario que sean agotados los procedimientos previstos en los artículos 48 a 50" de la $\mathrm{CADH}$, previsión contenida en el artículo 61 inc. 2 del citado instrumento. Lo veremos en el acápite que continúa.

\section{Normas procedimentales sobre la tramitación de peticiones y comunicaciones ante la Comisión y ante la Corte}

\subsection{Legitimación para presentar peticiones o efectuar comunicaciones ante la Comisión}

Hemos hecho mención a la dualidad que presenta el esquema de protección previsto por la $\mathrm{CADH}$, en el sentido de que prevé dos formas de iniciar un reclamo ante la Comisión, según quien fuere el legitimado activo.

En lo que refiere al régimen de peticiones, el artículo 44 de la CADH dispone -previendo una amplia legitimación- que "cualquier persona o grupo de personas, o entidad no gubernamental legalmente reconocida en uno o más Estados miembros de la Organización, puede presentar a la Comisión peticiones que contengan denuncias o quejas de violación de esta Convención por un Estado parte".

Hay que tener en cuenta que de la conjunción de los artículos 23 y 51 del Reglamento de la Comisión Interamericana de

25 Bidart Campos, German J., "Manual de la Constitución Reformada", T. III, Ed. Ediar, Buenos Aires, 1998, p. 555 
Derechos Humanos (en adelante, RCIDH) -aprobado por la Comisión, cuya redacción actual se encuentra en vigor desde el $1^{\circ}$ de agosto de 2013- se infiere que cualquier persona o grupo de personas, o entidad no gubernamental legalmente reconocida en uno o más Estados miembros de la OEA -aun cuando el Estado no fuera parte de la $\mathrm{CADH}$ - puede presentar a la Comisión peticiones en su propio nombre o en el de terceras personas, que contengan denuncias sobre presuntas violaciones de los derechos humanos consagrados en la DADDH por parte de dicho Estado. No obstante, la diferencia fundamental con aquella petición del artículo 44 de la $\mathrm{CADH}$ efectuada contra Estados miembros de la Convención, radica en que no puede remitirse el caso a la Corte, estando reservada esa posibilidad solo respecto de aquellos casos en que se encuentren involucrados Estados que, además de haber ratificado la $\mathrm{CADH}$, han aceptado la competencia de dicho tribunal -artículo 52 del RCIDH-.

No puede dejar de mencionarse que el artículo 24 del RCIDH otorga a la Comisión la facultad de iniciar la tramitación de un caso de oficio -tramitación proprio motu-, cuando considere que, a su juicio, se dan los requisitos para ello.

En lo que respecta a la regulación de las comunicaciones, el artículo 45 de la CADH dispone que "la Comisión tiene competencia para recibir y examinar las comunicaciones en que un Estado parte alegue que otro Estado parte ba incurrido en violaciones de los derechos bumanos establecidos en la CADH", aunque exige, para la procedencia de ejercicio de tal función, que el Estado reclamante -en el momento del depósito de su instrumento de ratificación o adhesión de la Convención, o en cualquier momento posterior- haya declarado que reconoce la competencia de la Comisión, sea por tiempo indefinido, por un período determinado o para casos específicos.

\subsection{Requisitos de admisibilidad por parte de la Comisión}

El artículo 46 de la CADH es claro en el sentido de que “...para que una petición o comunicación presentada conforme a los 
artículos 44 o 45 sea admitida por la Comisión, se requerirá: a) que se hayan interpuesto y agotado los recursos de jurisdicción interna, conforme a los principios del Derecho Internacional generalmente reconocidos; b) que sea presentada dentro del plazo de seis meses, a partir de la fecha en que el presunto lesionado en sus derechos haya sido notificado de la decisión definitiva; c) que la materia de la petición o comunicación no esté pendiente de otro procedimiento de arreglo internacional, y d) que en el caso del artículo 44 la petición contenga el nombre, la nacionalidad, la profesión, el domicilio y la firma de la persona o personas o del representante legal de la entidad que somete la petición." Párrafo seguido, el artículo establece supuestos de excepción a lo dispuesto por los incisos a) y b), al disponer que no se aplicarán en aquellas ocasiones en que “...a) no exista en la legislación interna del Estado de que se trata el debido proceso legal para la protección del derecho o derechos que se alega ban sido violados; b) no se baya permitido al presunto lesionado en sus derechos el acceso a los recursos de la jurisdicción interna, o baya sido impedido de agotarlos, y c) haya retardo injustificado en la decisión sobre los mencionados recursos."

A su vez, el artículo 47 impone una obligación en cabeza de la Comisión de declarar inadmisible la petición o comunicación, cuando compruebe la existencia de cuatro supuestos: “... a) falte alguno de los requisitos indicados en el artículo 46; b) no exponga bechos que caractericen una violación de los derechos garantizados por esta Convención; c) resulte de la exposición del propio peticionario o del Estado manifiestamente infundada la petición o comunicación o sea evidente su total improcedencia, y d) sea sustancialmente la reproducción de petición o comunicación anterior ya examinada por la Comisión u otro organismo internacional".

Es dable destacar que el artículo 36 inc. 2 del RCIDH aclara que la adopción del informe de admisibilidad no prejuzga sobre el fondo del asunto. A su vez, el inc. 3 del mismo artículo faculta a la Comisión a abrir el caso pero diferir el tratamiento de la admisibilidad hasta el debate y decisión sobre el fondo, cuando 
se presentaren circunstancias excepcionales, incluyéndose entre ellas: “...a. cuando la consideración sobre la aplicabilidad de una posible excepción al requisito del agotamiento de recursos internos estuviera inextricablemente unida al fondo del asunto; b. en casos de gravedad y urgencia o cuando se considere que la vida de una persona o su integridad personal se encuentran en peligro inminente; o c. cuando el transcurso del tiempo pueda impedir que la decisión de la Comisión tenga efecto útil."

\subsection{Procedimiento seguido por la Comisión en caso de admisión de la petición o comunicación}

Estemos ante peticiones individuales o comunicaciones estatales, una vez evaluados los requisitos antes previstos, y habiendo declarado la Comisión la admisibilidad del reclamo, la $\mathrm{CADH}$ regula idéntico procedimiento a seguir para ambas.

El artículo 48 de la CADH dispone que la Comisión, al recibir una petición o comunicación en la que se alegue la violación de cualquiera de los derechos consagrados por la Convención, procederá de la siguiente manera:

“a) Si reconoce la admisibilidad de la petición o comunicación solicitará informaciones al Gobierno del Estado al cual pertenezca la autoridad señalada como responsable de la violación alegada, transcribiendo las partes pertinentes de la petición o comunicación. Dichas informaciones deben ser enviadas dentro de un plazo razonable, fijado por la Comisión al considerar las circunstancias de cada caso";

"b y c) Recibidas las informaciones o transcurrido el plazo fijado sin que sean recibidas, verificará si existen o subsisten los motivos de la petición o comunicación: de no existir o subsistir, mandará archivar el expediente; podrá también declarar la inadmisibilidad o la improcedencia de la petición o comunicación, sobre la base de una información o prueba sobrevinientes".

Sobre este punto, es de trascendental importancia lo previsto por el artículo 38 del RCIDH: establece que se presumirán 
verdaderos los hechos alegados en la petición cuyas partes pertinentes hayan sido transmitidas al Estado en cuestión, si éste no suministra información relevante para controvertirlos dentro del plazo fijado por la Comisión, siempre que de otros elementos de convicción no resulte una conclusión contraria. A su vez, el artículo 42 del RCIDH establece que sin perjuicio de que la Comisión pueda decidir sobre el archivo del expediente cuando verifique que no existen o subsisten los motivos de la petición o caso -agregando también como supuestos de procedencia de archivo aquellos casos en que no se cuente con información necesaria para alcanzar una decisión sobre la petición, o cuando exista una injustificada inactividad procesal del peticionario que importe un indicio serio de desinterés en la tramitación de la petición-, ella está obligada a notificar a las partes la posibilidad de tomar tal decisión, a modo de instarlas a presentar información relevante para la resolución del asunto.

"d y e) Si el expediente no se ha archivado y con el fin de comprobar los hechos, la Comisión realizará, con conocimiento de las partes, un examen del asunto planteado en la petición o comunicación. Si fuere necesario y conveniente, la Comisión realizará una investigación para cuyo eficaz cumplimiento solicitará, y los Estados interesados le proporcionarán, todas las facilidades necesarias; podrá pedir a los Estados interesados cualquier información pertinente y recibirá, si así se le solicita, las exposiciones verbales o escritas que presenten los interesados".

A su vez, el párrafo $2^{\circ}$ otorga una importante facultad a la Comisión, al disponer que no obstante lo expuesto,

“...en casos graves y urgentes, puede realizarse una investigación previo consentimiento del Estado en cuyo territorio se alegue haberse cometido la violación, tan sólo con la presentación de una petición o comunicación que reúna todos los requisitos formales de admisibilidad".

En resumen, esta instancia está destinada a lograr el establecimiento de los hechos materia de controversia y su presunta violación a los Derechos protegidos por la Convención. 
"f) Se pondrá a disposición de las partes interesadas, a fin de llegar a una solución amistosa del asunto fundada en el respeto a los derechos humanos reconocidos en esta Convención".

Resulta relevante el esfuerzo realizado por la Comisión para el arribo de una solución que resuelva la controversia en forma amistosa. A todo evento, el articulo 49 dispone que si se ha arribado a la misma, "la Comisión redactará un informe que será transmitido al peticionario y a los Estados partes en esta Convención y comunicado después, para su publicación, al Secretario General de la Organización de los Estados Americanos....", debiendo contener dicho informe una "...breve exposición de los bechos y de la solución lograda..."

A renglón seguido, la $\mathrm{CADH}$ pasa a regular -aunque de manera confusa, embrollo luego aclarado por la Corte $^{26}$ - el procedimiento a seguir en caso de no llegarse a una solución amistosa. Ello puesto que la Comisión, lejos de ser un órgano llamado nada más que a investigar, y cuya tarea resida solo en establecer los hechos e intervenir como órgano de conciliación ${ }^{27}$, se encuentra facultada a pronunciarse respecto del fondo. El artículo 50 dispone que la Comisión deberá elaborar un informe, que será transmitido a los Estados interesados, en el que expondrá los hechos y sus conclusiones, agregándose en él las exposiciones verbales o escritas que hayan hecho los interesados en virtud del artículo 48 inc. 1.e.

El Artículo 44 del RCIDH incorpora algunos detalles al tratar el contenido de este informe, que refleja una verdadera tarea decisoria de la Comisión, en tanto dispone que luego de la deliberación y voto sobre el fondo del caso, la Comisión deberá proceder de la siguiente manera:

"1. Si establece que no hubo violación en un caso determinado, así lo manifestará en su informe sobre el fondo.

26 OC-13/93, 16/07/1993.

27 Faúndez Ledesma, Héctor, cit. p. 465. 
El informe será transmitido a las partes, y será publicado e incluido en el Informe Anual de la Comisión a la Asamblea General de la OEA".

"2. Si establece una o más violaciones, preparará un informe preliminar -aquel al que refiere el artículo 50 de la $\mathrm{CADH}-$ con las proposiciones y recomendaciones que juzgue pertinentes y lo transmitirá al Estado en cuestión. En tal caso, fijará un plazo dentro del cual el Estado en cuestión deberá informar sobre las medidas adoptadas para cumplir las recomendaciones".

Con referencia a ese mismo informe, el artículo 51 de la CADH agrega, en los párrafos 2 y 3, que en caso de establecer que existen violaciones, "la Comisión hará las recomendaciones pertinentes y fijará un plazo dentro del cual el Estado debe tomar las medidas que le competan para remediar la situación examinada", y que "transcurrido el período fijado, la Comisión decidirá, por la mayoría absoluta de votos de sus miembros, si el Estado ba tomado o no medidas adecuadas". Es clara la finalidad del plazo otorgado en el sentido de otorgar una chance al Estado de cumplir las recomendaciones sin necesidad de atravesar por el procedimiento contencioso que la $\mathrm{CADH}$ prevé -para el caso en que se trate de un Estado parte de ella-.

Es importante destacar aquí que, de acuerdo al Artículo 44 inc. 3 del RCIDH, la Comisión deberá notificar al peticionario la adopción del informe y su transmisión al Estado para dar cumplimiento de las recomendaciones efectuadas, ocasión en la cual, si se tratare de un Estado parte en la CADH que hubiera aceptado la jurisdicción contenciosa de la Corte -recordemos que, como se ha dicho, solo en tal caso existe posibilidad de llevar el caso a la Corte, no así en caso de peticiones contra Estados solo parte de la OEA, artículo 52 del RCIDH-, le dará al peticionario la oportunidad de presentar, dentro del plazo de un mes, su posición respecto del sometimiento del caso al tribunal. Si el peticionario tuviera interés en que la petición sea sometida finalmente a consideración de la Corte, deberá presentar los siguientes elementos: a. la posición de la víctima 
o sus familiares, si fueran distintos del peticionario; b. los fundamentos con base en los cuales considera que el caso debe ser remitido a la Corte; y c. las pretensiones en materia de reparaciones y costas.

\subsection{Procedimiento seguido ante la Corte}

El artículo 51 de la $\mathrm{CADH}$, en su inciso $1^{\circ}$, dispone que "si en el plazo de tres meses, a partir de la remisión a los Estados interesados del informe de la Comisión, el asunto no ba sido solucionado o sometido a la decisión de la Corte por la Comisión o por el Estado interesado, aceptando su competencia, la Comisión podrá emitir, por mayoría absoluta de votos de sus miembros, su opinión y conclusiones sobre la cuestión sometida a su consideración". Es por ello que este artículo establece un plazo cierto y preclusivo para someter el caso -comunicación o petición que originó el procedimiento organizado por la CADH y el RCIDH- a la Corte por la Comisión o por el Estado interesado, dentro del cual el Estado denunciado debe observar las recomendaciones y adoptar las medidas necesarias para solucionar la situación violatoria si desea evitar la instancia contenciosa.

$\mathrm{La} \mathrm{CADH}$ no contiene disposiciones detalladas respecto del procedimiento a seguir ante la Corte, en contraposición al Reglamento de la Corte, que sí las prevé. Señala el artículo 35 que el caso será sometido por la Comisión a la Corte mediante la presentación del informe al que se refiere el artículo 50 de la $\mathrm{CADH}$, que contenga todos los hechos supuestamente violatorios, inclusive la identificación de las presuntas víctimas y de sus representantes, nombres de los Delegados, los motivos que llevaron a la Comisión a presentar el caso ante la Corte, copia de la totalidad del expediente ante la Comisión, las pretensiones y reparaciones, y las pruebas que recibió, entre otras previsiones. El artículo 36, por su parte, reproduce casi en forma textual su precedente, para el caso de que quien someta el caso a la Corte fuere un Estado. 
El artículo 37 prevé que "en casos de presuntas víctimas sin representación legal debidamente acreditada, el Tribunal podrá designar un Defensor Interamericano de oficio que las represente durante la tramitación de caso".

Presentado el caso, el mismo se notifica a los jueces, el Estado demandado -quien expondrá por escrito su posición sobre el caso dentro del plazo de dos meses-, la Comisión -si no es ella quien presenta el caso-, y la presunta víctima, sus representantes o el Defensor Interamericano, si fuere el caso -quienes contarán con un plazo de dos meses, contado a partir de la recepción de este escrito y sus anexos, para presentar autónomamente a la Corte su escrito de solicitudes, argumentos y pruebas-.

Dispone el artículo 41 que el Estado, en la contestación, deberá indicar:" a. si acepta los hechos y las pretensiones o si los contradice; b. las pruebas ofrecidas; c. la propuesta e identificación de los declarantes y el objeto de su declaración; d. los fundamentos de derecho, las observaciones a las reparaciones $y$ costas solicitadas, así como las conclusiones pertinentes", pudiendo también oponer excepciones preliminares en dicho escrito -artículo 42-.

A continuación, prevé una instancia oral -artículos 51 y ss.-, audiencia ante la Corte donde la Comisión expondrá los fundamentos de la presentación, serán interrogados los declarantes convocados bajo promesa de decir verdad, y declararán las presuntas víctimas -libradas de efectuar promesa alguna-, hallándose facultados los jueces para efectuarles las preguntas que consideren pertinentes. Culminada esta fase, se le concederá la palabra a las presuntas víctimas o sus representantes y al Estado demandado para que expongan sus alegatos, y posteriormente la posibilidad de una réplica y una dúplica. Concluidos los alegatos, la Comisión presentará sus observaciones finales, y para finalizar, se les concederá la palabra a los jueces a efectos de que, si lo desean, formulen preguntas a la Comisión, a las presuntas víctimas o a sus representantes y al Estado. 
A todo evento, el artículo 58 refuerza las potestades de la Corte, al disponer que en cualquier estado de la causa podrá procurar de oficio toda prueba que considere útil y necesaria; oír en calidad de presunta víctima, testigo, perito o por otro título, a cualquier persona cuya declaración, testimonio, u opinión estime pertinente; requerir de la Comisión, de las víctimas o presuntas víctimas o sus representantes, del Estado demandado y, en su caso, del Estado demandante el suministro de alguna prueba que estén en condiciones de aportar o de cualquier explicación o declaración que, a su juicio, pueda ser útil; solicitar a cualquier entidad, oficina, órgano o autoridad de su elección, que obtenga información, que exprese una opinión o que haga un informe o dictamen sobre un punto determinado; y comisionar a uno o varios de sus miembros para que realicen cualquier medida de instrucción, en la sede de la Corte o fuera de ella.

Como se ve, las facultades de la Corte durante el procedimiento son amplísimas y de tinte inquisitivo. A mayor abundamiento, incluso en caso de desistimiento de quien hizo la presentación del caso, aceptación de los hechos o allanamiento total/parcial a las pretensiones por el demandado, o solución amistosa sobreviniente entre las partes -artículos 61 a 63-, la Corte, "teniendo en cuenta las responsabilidades que le incumben de proteger los derechos bumanos, podrá decidir que prosiga el examen del caso..." -artículo 64-.

Finalizada la etapa oral, el artículo 56 del Reglamento otorga facultad a las presuntas víctimas o sus representantes, el Estado demandado y, en su caso, el Estado demandante, de presentar alegatos finales escritos, y faculta también a la Comisión a que, si lo estima conveniente, presente observaciones finales escritas.

De acuerdo al artículo 65 del Reglamento, la sentencia deberá contener, entre otros elementos, una relación de los actos del procedimiento; la determinación de los hechos; las conclusiones de las partes; los fundamentos de derecho; la decisión sobre el caso; y el pronunciamiento sobre las reparaciones y costas, si procediere; todo ello, en consonancia con lo dispuesto 
por el artículo 66 de la $\mathrm{CADH}$, que dispone que el fallo de la Corte deberá ser motivado, y que los jueces tendrán derecho a votar en forma disidente, agregándose al fallo su opinión.

El fallo de la Corte será notificado a las partes en el caso y transmitido a los Estados partes en la Convención -artículo 69 de la $\mathrm{CADH}-$, siendo definitivo e inapelable -artículo 67 de dicho instrumento-. A renglón seguido, dispone el artículo 68 que "los Estados partes en la Convención se comprometen a cumplir la decisión de la Corte en todo caso en que sean partes", y que "la parte del fallo que disponga indemnización compensatoria se podrá ejecutar en el respectivo país por el procedimiento interno vigente para la ejecución de sentencias contra el Estado".

De acuerdo al artículo 76 del Reglamento, "la Corte podrá, a iniciativa propia o a solicitud de parte, presentada dentro del mes siguiente a la notificación de la sentencia o resolución de que se trate, rectificar errores notorios, de edición o de cálculo" notificando en tal caso a la Comisión, las víctimas o sus representantes, al Estado demandado y, en su caso, al Estado demandante.

Prevé también el artículo 67 de la CADH que "en caso de desacuerdo sobre el sentido o alcance del fallo, la Corte lo interpretará a solicitud de cualquiera de las partes, siempre que dicha solicitud se presente dentro de los noventa dias a partir de la fecha de la notificación del fallo", agregando el artículo 68 del Reglamento que "la solicitud de interpretación no suspenderá la ejecución de la sentencia”

Como conclusión del procedimiento, el artículo 69 del Reglamento prevé herramientas de supervisión de cumplimiento de las sentencias del Tribunal, otorgando amplias facultades a la Corte para requerir datos que permitan apreciar el cumplimiento, peritajes e informes que considere oportunos, e incluso convocar al Estado y a los representantes de las víctimas a una audiencia para supervisar la ejecución de sus decisiones.

Es de interés destacar que la $\mathrm{CADH}$ no prevé mecanismos de coacción a los efectos de lograr el acatamiento forzado de las 
sentencias emanadas de la Corte. Sin embargo, en su artículo 65 establece que la Corte someterá a la consideración de la Asamblea General de la Organización un informe sobre su labor en el año anterior, señalando especialmente los casos en que un Estado no haya dado cumplimiento a sus fallos. De todas formas, tampoco se han establecido herramientas coactivas a emplear por la Asamblea contra el Estado incumplidor, aunque se ha sostenido que por ser la protección de los derechos humanos la función más importante a desempeñar por la OEA, sería viable que la Asamblea resolviera que el gobierno incumplidor, por voluntad propia, se ha colocado al margen del sistema interamericano, excluyéndolo en tal sentido de participar en la OEA. ${ }^{28}$

\section{5. ¿Pérdida de supremacía de nuestra Corte Suprema de Justicia Nacional?}

Se ha sostenido que en virtud de la regulación analizada, la decisión de la Corte bien puede dejar sin efecto la resolución de una autoridad argentina (incluso una sentencia de la CSJN) si la considera violatoria de los Derechos Humanos consagrados en la $\mathrm{CADH}$; y que, por esta razón, desde el acatamiento que Argentina ha hecho de la jurisdicción supraestatal de la Corte, la CSJN ha dejado en verdad de ser "suprema", puesto que sus decisiones no resultan últimas e irrevisables, perdiendo fuerza de cosa juzgada material ${ }^{29}$ ante lo que se ha llamado una justicia de tipo transnacional ${ }^{30}$, erigida como autoridad supranacional ${ }^{31}$

A ello se ha respondido que, en verdad, el calificativo de "Suprema" que a la CSJN le adjudica nuestra Constitución debe entenderse referido a la jurisdicción interna, como órgano máximo que en ella encabeza al poder judicial ${ }^{32}$. A su vez, se ha

\footnotetext{
28 Faúndez Ledesma, Héctor, cit. pp. 917-918.

29 Sagüés, Néstor Pedro, cit., pp. 617-618.

30 Ibídem, pp. 394-395.

31 Ibídem, p. 67

32 Bidart Campos, Germán J., "Manual”, T. III, cit., p. 340
} 
agregado que cuando se dice que un tribunal supraestatal como la Corte puede "revisar" las sentencias de la CSJN, se incurre en error, puesto que tal actividad no puede ser llamado "revisión" propiamente dicha de lo decidido por el máximo tribunal argentino, fundamentalmente por tres razones ${ }^{33}$ :

a) la primera, porque "la Corte Interamericana no actúa como tribunal de alzada respecto del tribunal argentino que falló en sede interna, ni revisa - por ende-su sentencia. Se trata de un proceso internacional que es independiente del tramitado ante tribunal argentino, o sea, de un "nuevo juicio" distinto del anterior finiquitado en sede interna";

b) la segunda, porque "el juzgamiento internacional no implica un nuevo juicio sobre la "misma materia" juzgada en sede interna, puesto que lo que la Corte Interamericana decide con fuerza de cosa juzgada versa sobre la interpretación y aplicación de la CADH, en orden a establecer si el estado parte (en el caso, Argentina) ba violado o no un derecho o una libertad contenidos en la misma Convención"

c) la tercera, porque la cosa juzgada de la sentencia argentina es lo que exactamente hay que obtener - como principiopara luego poder acudir a la jurisdicción supraestatal.

Por ello, se ha concluido que ni la Corte Interamericana es un tribunal que revisa -o eventualmente "revoca" - sentencias argentinas, ni la Corte Suprema de Justicia ha dejado de ser "Suprema" (y última instancia en nuestra jurisdicción interna). Constituyen en verdad dos jurisdicciones separadas que no intervienen en un mismo proceso $^{34}$.

33 Ibídem, pp. 557-558.

34 Ídem. 